\title{
Displacement, velocity preference, and substrate use of three native California stream fishes in simulated pulsed flows
}

\author{
Stephanie N. Chun - Sarah A. Cocherell • Dennis E. Cocherell • \\ Javier B. Miranda • Gardner J. Jones • Justin Graham • A. Peter Klimley • \\ Lisa C. Thompson • Joseph J. Cech Jr
}

Received: 1 October 2009 /Accepted: 24 August 2010/Published online: 8 September 2010

(C) The Author(s) 2010. This article is published with open access at Springerlink.com

\begin{abstract}
We studied whether juvenile fishes were able to maintain swimming speed and position during simulated river pulsed flows in a laboratory flume. We used a glass flume $(15.24 \times 0.6 \mathrm{~m})$ with riverrock substrate to determine the longitudinal displacement, movement distances and frequencies, velocity selection, and substrate use of juvenile (SL range: 6.1 \pm $0.2 \mathrm{~cm})$ hardhead Mylopharodon conocephalus $(n=13)$,
\end{abstract}

\section{S. N. Chun}

Department of Water Resources,

3310 El Camino Avenue, Suite 110,

Sacramento, CA 95821, USA

S. A. Cocherell • D. E. Cocherell • J. B. Miranda •

G. J. Jones · A. P. Klimley • L. C. Thompson $(\bowtie)$ •

J. J. Cech Jr

Wildlife, Fish, \& Conservation Biology Department,

University of California Davis,

1 Shields Avenue,

Davis, CA 95616-8751, USA

e-mail: lcthompson@ucdavis.edu

J. Graham

Ecological Engineering Research Program,

University of the Pacific,

3601 Pacific Ave.,

Stockton, CA 95211, USA

Present Address:

J. B. Miranda • G. J. Jones

California Department of Water Resources,

1416 9th Street, Room 252-35,

Sacramento, CA 95814, USA rainbow trout Oncorhynchus mykiss $(n=11)$, and Sacramento sucker Catostomus occidentalis $(n=12)$ during a 100 -min flow pulse, as velocity changed from slow to medium, fast, medium, and slow. Fish were capable of maintaining swimming speed and position up to the maximum flume velocity of $0.46 \mathrm{~m} \cdot \mathrm{s}^{-1}$, except for one hardhead that impinged on the rear fish screen. Fish swam faster in the flume during the medium and fast intervals than the slow intervals, but fish speeds were similar among the medium and faster intervals, when some fish took cover behind the rock substrate. In comparison with a Brett-type swim-tunnel, fish showed less increase in mean swimming speed as the flume velocity increased. Fish in the flume were able to use the rock substrate as hydraulic cover, decreasing the encountered water velocity, and, presumably, conserving energy.

Keywords Pulsed flows · Longitudinal displacement . Hardhead Mylopharodon conocephalus · Rainbow trout Oncorhynchus mykiss $\cdot$ Sacramento sucker Catostomus occidentalis

\section{Introduction}

Human-controlled flow pulses from reservoirs are common in rivers around the world (Young et al. 2007). In California, river flows may be pulsed for electrical power generation (daily) or for recreational, white-water rafting (daily to monthly). These releases 
differ from those related to crop irrigation or flood control because of their short duration at some regular frequency. Managers must balance these flow requirements with the habitat-related needs of a river's resident biota, but the impacts of pulsed flows on the resident fishes are relatively unknown.

Native Californian fish species have evolved with seasonal flow fluctuations (Moyle 2002), but the increased frequency of these fluctuations (e.g., for electricity generation) and late-warm-season timing (for recreational purposes) represent significant deviations from the natural hydrograph. A potential consequence of regulated flows is downstream displacement of fish. Previous studies have documented downstream movement of larval salmonids exposed to increasing flows in artificial streams (Ottaway and Clarke 1981; Ottaway and Forrest 1983; Crisp 1991; Crisp and Hurley 1991a, b). Irvine (1986) observed increased downstream displacement of Chinook salmon Oncorhynchus tshawytscha fry during daily flow fluctuations in experimental stream channels, but this occurred only during the first 2 weeks of the study. Longitudinal displacement of juvenile coho salmon O. kisutch has been observed in streams during winter periods when floods are common (Shirvell 1994; Giannico and Healey 1998; Bell et al. 2001). During flood events Harvey (1987) found that juvenile centrarchids and cyprinids $<10 \mathrm{~mm}$ TL were susceptible to downstream displacement. Adult Sacramento suckers Catostomus occidentalis fitted with radio transmitters showed a mean, ca. $2-\mathrm{km}$ displacement downstream after a flow pulse in California's Mokelumne River (Jeffres et al. 2006).

Our objective in this study was to determine the effects of a pulsed flow on juveniles of three native fish species: hardhead Mylopharodon conocephalus, rainbow trout $O$. mykiss, and Sacramento suckers. We chose these species in order to study native California fishes with a range of body types and potential swimming abilities, that are all present in California rivers under the influence of dams and pulsed flows. We simulated a flow pulse in a long laboratory flume, with stepped increases followed by stepped decreases in water velocity within a range of 0 to $0.46 \mathrm{~m} \cdot \mathrm{s}^{-1}$. Our metrics were fishes' longitudinal displacement, movement distances and frequencies, velocity selection, and substrate use. We also conducted pilot tests in a Brett-type swim-tunnel (Brett 1964) to ensure that flume velocities were sufficient to displace non- swimming fish, and to correlate swimming activity and behavior with velocities in a more controlled situation, without objects that fish could use to take shelter from the flow.

\section{Methods}

Fish collection and handling

In April 2004, age-0 hardhead were collected from Slab Creek, a tributary of the South Fork American River in California, with a 6.1-m beach seine, and baited minnow traps. We placed fish into oxygenated plastic bags of creek water in a plastic transport cooler, then drove them immediately (2-h trip) to the UC Davis Center for Aquatic Biology and Aquaculture (CABA). We obtained rainbow trout from the California Department of Fish and Game's (CDFG) American River Trout Hatchery, Rancho Cordova, and transported them to CABA (45-min trip) in oxygenated plastic bags of American River water. We captured Sacramento suckers by electrofishing in three, $50-\mathrm{m}$ reaches of Putah Creek on the UC Davis campus, and transported them in a plastic transport cooler to CABA (5-min trip).

We housed fish at CABA in 250-1 circular tanks equipped with flow-through, air-equilibrated well water (conductivity $670 \mu \mathrm{S} \mathrm{cm} \mathrm{cm}^{-1}$, dissolved oxygen $9.1 \mathrm{mg} \mathrm{l}^{-1}$, and $\mathrm{pH} \mathrm{8.1)}$ under natural photoperiod conditions at $14^{\circ} \mathrm{C}$. A 10 -d disease-prevention treatment, consisting of malachite formalin $\left(0.036 \mathrm{ml} \mathrm{l}^{-1}\right)$ and nitrofurazone $\left(10 \mathrm{~g} \mathrm{l}^{-1}\right)$, was administered immediately after fish arrived at the facility. We cleaned the tanks and fed fish semi-moist feed (Rangen, Inc., Buhl, ID) daily. Regular checks were made of dissolved oxygen (always $>8.5 \mathrm{mg} \mathrm{l}^{-1}$ ) and dissolved ammonia (always $<0.3 \mathrm{mg} \mathrm{l}^{-1}$ ) levels.

Experimental apparatus and testing procedure

The 16.5-m-long by 0.6-m-wide experimental glass flume, located at the J. Amorocho Hydraulics Laboratory on the UC Davis campus, held 4,542 1 at a depth of $17.8 \mathrm{~cm}$ and incorporated a variable-speed motor and propeller to move water through the system (Danley et al. 2002). Water moved through a 25.4-cm-diameter pipe to one end of the flume and flowed through the open-topped glass flume to the opposite end for recirculation (Fig. 1). The length of the experimental 
Fig. 1 Side-view of the flume, of $59.1 \mathrm{~cm}$ width showing flow direction and flume dimensions. The variable-speed motor and propeller (circulation pump) propels water under the chamber and through flow straighteners before entering the experimental area located between the fish screens.

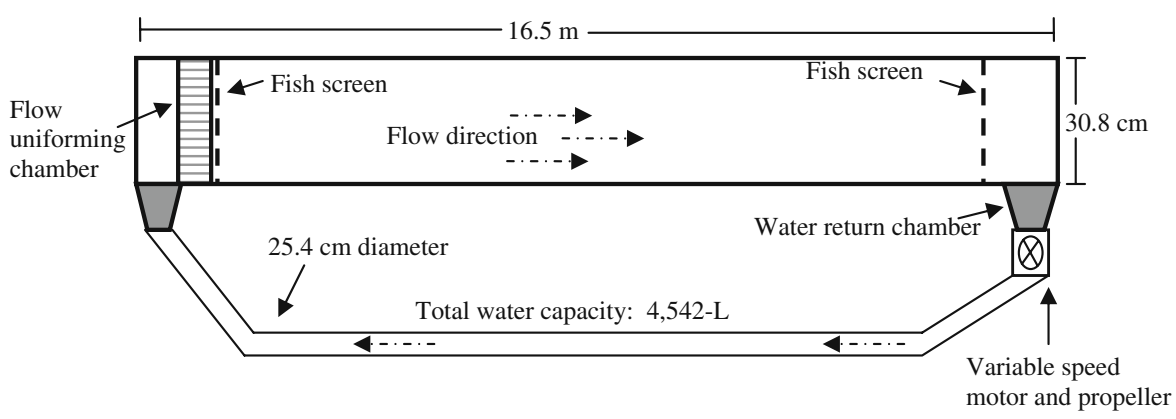

area was $15.24 \mathrm{~m}$. Flume temperature $\left(14 \pm 1^{\circ} \mathrm{C}\right)$ was regulated during experiments by exchanging small amounts of water between the flume and a temperature-regulated, underground sump filled with the well water.

The flume's interior (Fig. 2) consisted of areas without substrate, areas with small rock, large rock, or
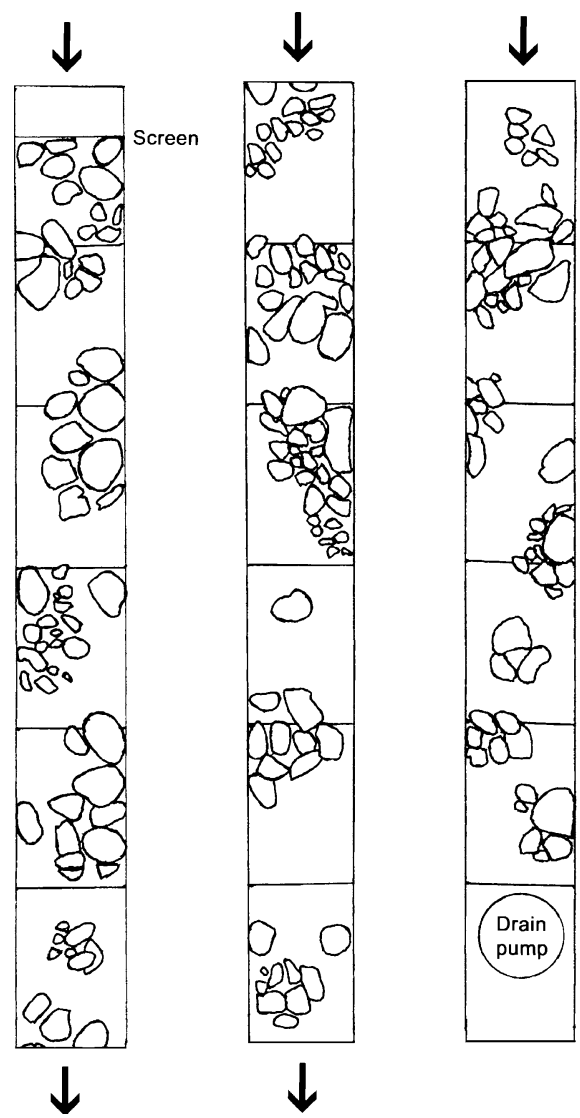

Fig. 2 Arrangement of artificial substrate in the flume. The interior is shown in three sections, due to its length. The upstream area is shown in the top left corner while the downstream area is located near the drain pump in the lower right corner. Rock locations are outlined along $0.9 \mathrm{~m}$ flume sections. a mixture. The rock substrate was attached to clear Plexiglass ${ }^{\circledR}$ sheets, which rested on the flume's bottom. Substrate patterns were based on streambed observations and measurements on the South Fork American River. Natural rock substrate ranged in size from 3.2 to $25.6 \mathrm{~cm}$ in diameter and consisted of $37 \%$ very coarse gravel, $45 \%$ small cobble, and $18 \%$ large cobble, according to a bed and bank material characterization chart (Harrelson et al. 1994). Smaller rock and sand could not be used, because they could shift within and between experiments, changing the substrate pattern experienced by successive fish.

The experimental, pulsed-flow regime simulated a hypothetical sequence of velocities designed to mimic daily pulses. The 100-min pulse contained a five-stage sequence of 20-min velocity intervals: slow, medium, fast, medium, and slow (Table 1). To estimate flume velocities we measured fifty randomly selected locations with a flow meter (Marsh-McBirney Inc., Flo-Mate 2000). The experiments were of shorter duration than a typical pulse in a regulated river because the fish were not fed during the experiment.

We tested hardhead, rainbow trout, and Sacramento suckers in the flume from July to September, 2004 (Table 2). One fish at a time was exposed to the flume per experiment to allow accurate tracking of an

Table 1 Mean $( \pm$ SE) flume water velocities and time spent by hardhead, rainbow trout, and Sacramento suckers in the flume during acclimation and the five experimental velocity intervals.

Velocity Interval Water Velocity $\left(\mathrm{m} \cdot \mathrm{s}^{-1}\right)$ Time Interval (min)

\begin{tabular}{lll}
\hline Acclimation & 0.0 & 30 \\
Slow & $0.10 \pm 0.0$ & 20 \\
Medium & $0.31 \pm 0.0$ & 20 \\
Fast & $0.46 \pm 0.0$ & 20 \\
Medium & $0.31 \pm 0.0$ & 20 \\
Slow & $0.10 \pm 0.0$ & 20
\end{tabular}


Table 2 Mean $( \pm \mathrm{SE})$ standard lengths and wet weights of the juvenile fishes.

\begin{tabular}{llll}
\hline Species & $\mathrm{n}$ & SL $(\mathrm{cm})$ & Mass $(\mathrm{g})$ \\
\hline Hardhead & 13 & $6.1 \pm 0.2$ & $5.4 \pm 0.5$ \\
Rainbow trout & 11 & $5.0 \pm 0.2$ & $2.6 \pm 0.4$ \\
Sacramento sucker & 12 & $7.0 \pm 0.2$ & $6.7 \pm 0.5$ \\
\hline
\end{tabular}

individual fish's movements and behavior, and to avoid behavioral interactions between fish that would have confounded flow effects. We transported each fish to the flume in a polyethylene bucket filled with water, and released the fish between two temporary mesh crowders (set at 6.5 and $8.5 \mathrm{~m}$ from the upstream end) in the flume. Fish were acclimated in the center of the flume for $30 \mathrm{~min}$ with no flow, and pre-experiment water temperature was recorded.

At the beginning of each experiment we removed the crowders and gradually $(<2 \mathrm{~min})$ increased the water velocity from zero to the slow velocity. We recorded location, substrate use, swimming activity, and overall behavior in 5-min segments. We recorded fish location relative to the flume's length (x-dimension, measured from the upstream screen), distance from a reference wall (flume width: y-dimension), and the elevation above the bottom (flume depth: z-dimension). After $20 \mathrm{~min}$, we changed the water velocity to the next speed (medium). We continued this sequence until the fish had been exposed to the increasing and decreasing stepped sequence of the three flow velocities (100 min), or the fish was displaced and impinged on the downstream screen. We measured water velocities at the locations at which the fish was observed during the five successive flow rates. All measurements were taken in the absence of the subject to prevent altering fish behavior during experiments.

We determined the four water-velocity-correlated swimming activity levels in the modified Brett-type, recirculating swim-tunnel (Brett 1964). We defined swimming activity levels as: not swimming (body stationary), holding (intermittent fin or body movements, without positional change in the flume), routine swimming (continuous body undulations, which may be associated with positional change in the flume), or burst swimming (high-frequency body undulations associated with positional change in the flume). Experiments began at the end of a $50-\mathrm{min}$ acclimation period at $0.012 \mathrm{~m} \cdot \mathrm{s}^{-1}$, while chamber temperature was maintained at $14 \pm 1^{\circ} \mathrm{C}$.
Five rainbow trout and five hardhead were exposed to incremental increases in current, and observations of position, swimming behavior, and tail beat frequency were recorded at each velocity. We allowed fish enough time ( 2 to $10 \mathrm{~min}$ ) to adjust to the swim-tunnel velocity and to exhibit a consistent swimming behavior. These behavioral assessments were repeated, with water velocity increased in $0.029 \mathrm{~m} \cdot \mathrm{s}^{-1}$ increments until the fish displayed either burst swimming or fatigue.

\section{Data analyses}

We compared fish position in the flume, movement, fish point velocity, and substrate use versus flume velocity and species. We used one-way repeated-measures ANOVA (parametric) or Friedman repeated measures ANOVA on ranks (non-parametric) to make comparisons within species, among velocities. We used one-way ANOVA (parametric) or Kruskal-Wallis one-way ANOVA on ranks (non-parametric) to make comparisons between species, among velocities. We considered results significant at $\alpha<0.05$ for all tests. Significant tests were followed by an all pairwise multiple comparison procedure (one-way RM ANOVA: Holm-Sidak method, Friedman RM ANOVA on ranks: Dunn's method, Kruskal-Wallis one-way ANOVA on ranks: Dunn's method). For each of hardhead and rainbow trout we compared swim-tunnel velocity and flume velocity at each swimming activity level, using a Mann-Whitney rank sum test. Data analyses and plotting were performed using Sigmastat ${ }^{\circledR} \quad 3.0$, and Sigmaplot ${ }^{\circledR} \quad 8.0$ software packages.

\section{Results}

Although most of the fish moved freely within the flume, one hardhead impinged on the back screen 53 min into an experiment, $13 \mathrm{~min}$ into the fast velocity interval. This fish was not included in further analyses because of differences in its behavior, compared with those of the other hardhead. This was the only complete displacement observed in the flume, and this fish was one of the smaller fish tested (5.6 cm SL, $3.43 \mathrm{~g}$ wet weight).

Flume location

The mean longitudinal (x) locations of all species were either within the 2-m-long acclimation area of 
the flume, or $\leq 1.25 \mathrm{~m}$ outside it, regardless of pulsesimulation stage (Table 3). Hardhead were located further upstream during the second slow interval than during the fast interval. Rainbow trout mean location did not differ significantly between velocity intervals. Sacramento suckers were located downstream of the acclimation area during the first slow interval, but moved significantly upstream during the fast interval and maintained that position during the subsequent intervals. Hardhead and rainbow trout positions were significantly upstream of Sacramento suckers during the first slow interval, and rainbow trout were significantly upstream of hardhead and Sacramento suckers during the first medium interval. There was no difference in species location during the subsequent intervals.

\section{Longitudinal movement}

For all species, there were no differences in the distances moved among velocity intervals (Table 4). However, during the first slow interval rainbow trout moved upstream relative to the other species, and Sacramento suckers moved downstream. Although fish showed no significant net movement between intervals, they showed some movement upstream and downstream within each interval (Fig. 3). Movement frequencies were similar among species and intervals, but during the second slow interval Sacramento suckers moved downstream significantly more often than rainbow trout.

\section{Water velocity selection}

In general, fish responded to the simulated pulse by swimming faster as the flume velocity increased, and more slowly as the flume velocity decreased (Fig. 4). However, water velocities at locations occupied by fish were less than the average flume velocity during each interval, except at locations selected by rainbow trout during the second slow interval. Hardhead swimming velocities increased from the slow interval to the medium and fast intervals, then declined during the second slow interval, but did not differ significantly between the medium and fast intervals (Fig. 4). Rainbow trout swimming velocities increased progressively, from the first slow, to the medium and fast intervals, then leveled off. Trout swimming velocity during the fast interval was significantly higher than during the first slow interval, but changes in swimming velocity between adjacent intervals were not statistically significant (Fig. 4). Sacramento suckers showed a pattern of increased swimming velocity during the medium and fast velocity intervals (Fig. 4), but swimming velocity was highly variable, and often did not differ significantly between intervals. Rainbow trout selected higher velocity water than hardhead and Sacramento suckers during the first slow interval (Fig. 4). However, during the first medium interval hardhead selected significantly higher velocity water than did rainbow trout. During the fast and second medium intervals the water velocities selected were similar among species. During the second slow interval rainbow trout and Sacramento sucker selected higher velocity water than did hardhead.

Water velocity and swimming activity level

In general, increased swimming activity was correlated with lower water velocities in the flume than in the Brett-type swim-tunnel (Fig. 5). Velocities were significantly higher in the swim-tunnel than the flume
Table 3 Mean ( \pm SE) locations along the flume's length (m, measured from the upstream screen) for hardhead, rainbow trout, and Sacramento suckers. Fish were acclimated in the center of the flume between 6.5 and $8.5 \mathrm{~m}$. Different super- scripted letters indicate significantly different locations for a species among velocity intervals. Different superscripted numbers indicate significantly different locations among species, within a velocity interval.

\begin{tabular}{lrrrrr}
\hline Species & \multicolumn{2}{l}{ Velocity Intervals } & & & \\
\cline { 2 - 6 } & \multicolumn{1}{l}{ Slow } & Medium & Fast & Medium & Slow \\
\hline Hardhead & $7.69^{\mathrm{ab} 1} \pm 0.23$ & $7.65^{\mathrm{ab} 3} \pm 0.44$ & $7.94^{\mathrm{a}} \pm 0.41$ & $6.69^{\mathrm{ab}} \pm 0.62$ & $6.42^{\mathrm{b}} \pm 0.65$ \\
Rainbow trout & $6.49^{1} \pm 0.47$ & $5.25^{4} \pm 0.44$ & $6.15 \pm 0.43$ & $6.13 \pm 0.55$ & $5.80 \pm 0.57$ \\
Sacramento sucker & $9.21^{\mathrm{a} 2} \pm 0.53$ & $8.34^{\mathrm{a} 3} \pm 0.76$ & $6.55^{\mathrm{b}} \pm 0.77$ & $6.31^{\mathrm{b}} \pm 0.73$ & $6.13^{\mathrm{b}} \pm 0.74$ \\
\hline
\end{tabular}


Table 4 Mean $( \pm$ SE) total movement distances $(m)$, upstream (+ numbers) or downstream (- numbers), for each velocity interval. Different superscripted numbers indicate the significant difference between rainbow trout and Sacramento suckers for the $1^{\text {st }}$ slow interval.

Movement (m)

\begin{tabular}{|c|c|c|c|c|c|}
\hline \multirow[b]{2}{*}{ Species } & \\
\hline & Slow & Medium & Fast & Medium & Slow \\
\hline Hardhead & $-0.93 \pm 0.76$ & $-0.11 \pm 1.18$ & $1.6 \pm 0.80$ & $0.27 \pm 1.51$ & $0.62 \pm 0.97$ \\
\hline Rainbow trout & $2.00^{1} \pm 1.31$ & $-0.06 \pm 1.51$ & $-0.82 \pm 1.24$ & $-0.98 \pm 0.91$ & $0.42 \pm 2.34$ \\
\hline Sacramento sucker & $-2.55^{2} \pm 1.53$ & $2.56 \pm 1.99$ & $0.40 \pm 1.40$ & $1.65 \pm 0.94$ & $-2.38 \pm 1.37$ \\
\hline
\end{tabular}

when hardhead showed holding or routine swimming. Velocities were higher in the swim-tunnel than the flume when rainbow trout showed holding, routine, and burst swimming. Both hardhead and rainbow trout consistently showed burst swimming in the swim-tunnel at water velocities less than the maxima measured in the flume (mean \pm SE for flume $0.46 \pm$ $\left.0.0 \mathrm{~m} \cdot \mathrm{s}^{-1}\right)$.

Each species responded to the pulse simulations with unique swimming behavior (Fig. 6). Hardhead and Sacramento suckers did not swim during the majority of the slow intervals, while rainbow trout
Fig. 3 Mean (+ SE) hardhead $(n=12)$, rainbow trout $(n=11)$ and Sacramento sucker $(n=12)$ movements during each velocity interval. Fish were acclimated in the center of the flume (between 6.7 and $8.5 \mathrm{~m}$ ) before beginning the experiment. Different numbers indicate significantly different number of movements among species within a velocity interval.

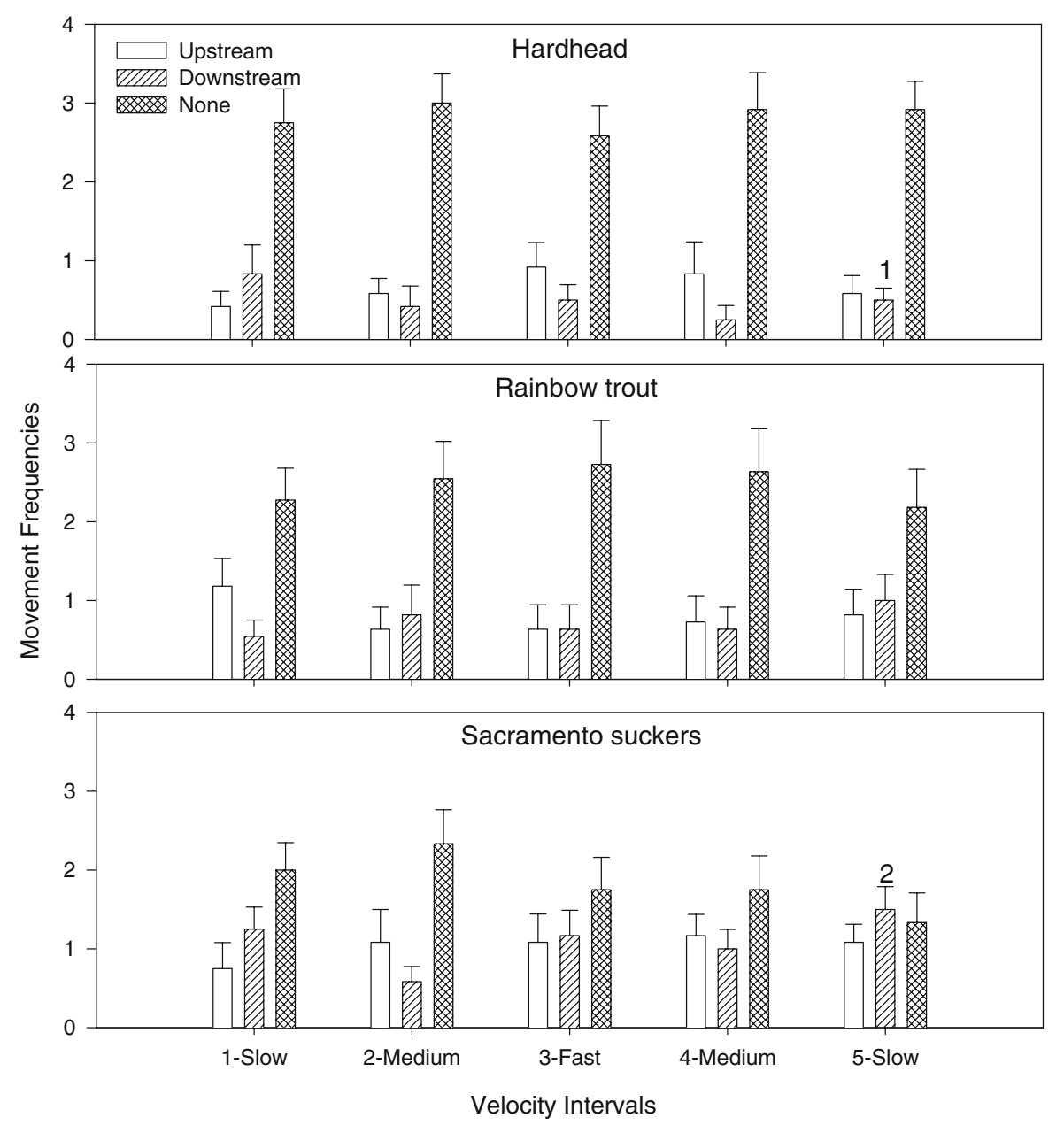




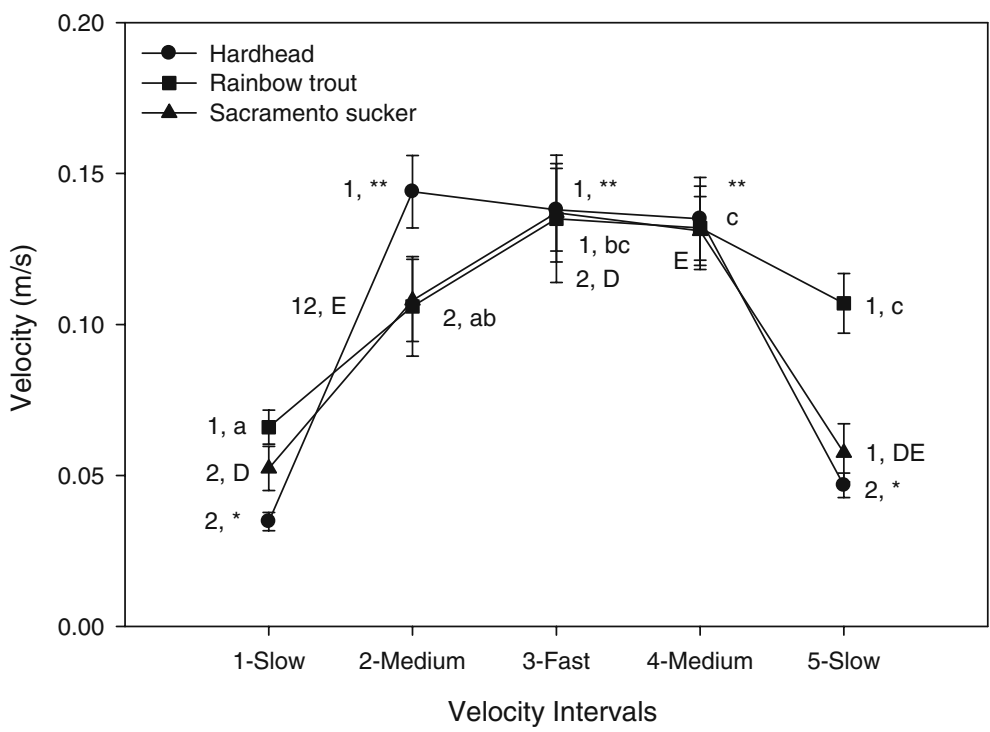

Fig. 4 Comparison of hardhead, rainbow trout, and Sacramento sucker's mean $( \pm \mathrm{SE})$ swimming velocities during slow, medium, and fast intervals in the glass flume. Different symbols $(*, * *)$ indicate significantly different velocities within hardhead, among velocity intervals. Different lower case letters $(a$, $b, c)$ indicate different velocities within rainbow trout, among

spent over half the slow interval swimming at either holding or routine activity levels. As flume velocity increased, all three species increased the percentage of their time spent routine and burst swimming. Sacramento suckers swam very little except for the fast velocity interval. Sacramento suckers were the least active, and rainbow trout the most active. velocity intervals. Different upper case letters $(D, E)$ indicate significantly different velocities within Sacramento suckers, among velocity intervals. Different numbers $(1,2)$ indicate significantly different velocities among species, within a velocity interval.

\section{Substrate selection}

Five hardhead, four rainbow trout, and two Sacramento suckers remained over substrate throughout the experiment. Hardhead and rainbow trout substrate use during pulse simulations did not differ among species nor among velocity intervals (Fig. 7). Sacramento
Fig. 5 Swimming activity levels exhibited at mean $( \pm \mathrm{SE})$ water velocities for hardhead $(\mathrm{HH})$ and rainbow trout (RT) in a Brett-type swim-tunnel versus in the flume. Different lower case letters $(a, b)$ indicate different velocities for a given swimming activity within hardhead. Different upper case letters $(C, D)$ indicate different velocities for a given swimming activity within rainbow trout.

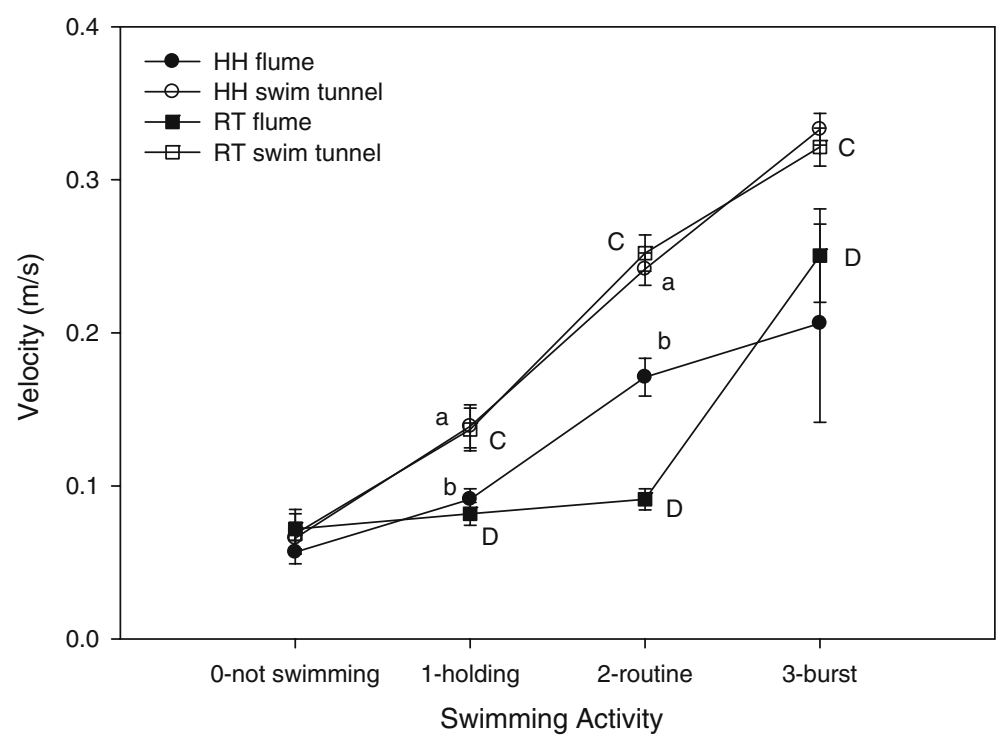


Fig. 6 Mean (+ SE) percentages of time spent in each swimming activity level at each velocity interval for hardhead $(n=12)$, rainbow trout $(n=11)$, and Sacramento sucker $(n=12)$.

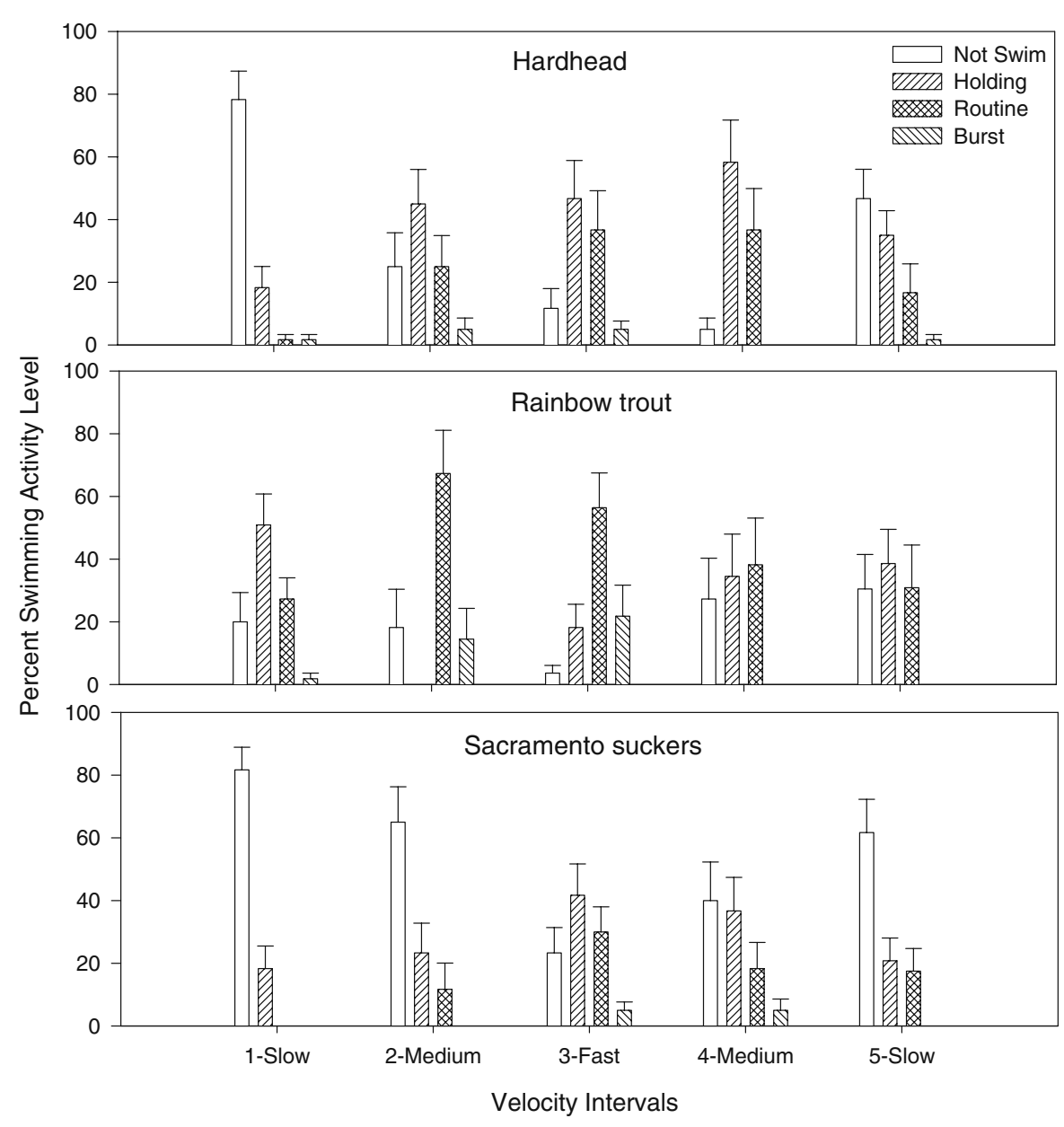

Fig. 7 Percentages of time $($ mean + SE) that hardhead $(\mathrm{HH})$, rainbow trout (RT), and Sacramento sucker (SS) were observed over rocky substrate during the five velocity intervals. Different numbers indicate significantly different substrate use percentages among species, within a velocity interval. Different letters indicate significantly different Sacramento sucker substrate use among velocity intervals.

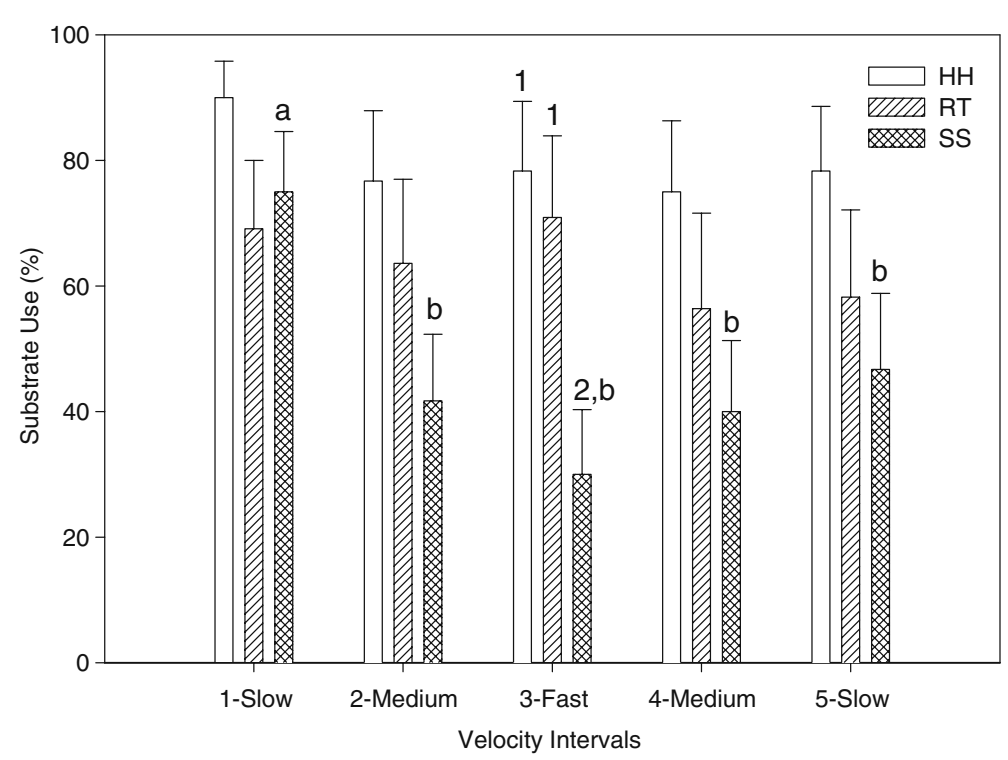


suckers were observed over substrate more during the first slow interval than during subsequent velocity intervals. During the fast velocity interval hardhead and rainbow trout used the substrate areas more than Sacramento suckers.

\section{Discussion}

Juvenile hardhead, rainbow trout, and Sacramento sucker generally remained in the section of the flume to which they were introduced, throughout the pulsedflow period, except for one hardhead that impinged on the back screen. Susceptibility to displacement by high flows may decrease with increasing fish size (Irvine 1986; Heggenes 1988). Swimming performance (sensu Brett 1964 in $\mathrm{cm} \cdot \mathrm{s}^{-1}$ ) generally increases with increasing fish length (Beamish 1978), in part due to increases in aerobic (red) muscle proportions at the caudal peduncle (Goolish 1989; McLaughin and Kramer 1991). The impinged hardhead's small size may have contributed to its inability to hold station in the flume at the fastest velocities. Our results are similar to field observations of a single-day pulse in a tributary of the South Fork American River, California (Klimley et al. 2005). Counts of young-of-the-year and juvenile trout were $26 \%$ and $9 \%$ lower after the pulse, respectively, presumably due to downstream displacement of smaller fish.

The choice to observe fish swimming behavior in a controlled laboratory flume setting involved obvious trade-offs. In order to isolate the influence of water velocity and substrate we did not simultaneously include variables such as the presence of food items, nor the presence of conspecifics or predators. We did not vary temperature in our experiments, although temperature differences are known to affect fishes' swimming performance (Beamish 1978; Heggenes and Traaen 1988; Hammer 1995; Myrick and Cech 2000). We did not use smaller rock and sand in the flume experiments, since they would have washed into the flume sump, although movement of these substrates can occur in natural systems, and potentially affect localized velocities and refuge areas. We also chose not to test the effects of repeated, successive pulses on the same fish, since fish were not fed during the trials. In field settings cumulative effects of multiple variables probably do occur, and should be taken into account by flow managers. However, our results do offer some insights into the ways juvenile fishes may respond to pulsed flows in rivers.

Although water velocities during river pulsed flows may greatly exceed the range possible in the flume, most fish responded by swimming faster during the medium and fast intervals, indicating that our flume velocities were adequate to affect fish swimming behavior. Furthermore, fish used the substrate to occupy locations with lower velocities than the average flume velocity, particularly during the medium and fast intervals. Water velocities were especially variable in certain flume locations, in part due to turbulence and eddies created by the substrate elements. Areas partially or fully surrounded by cobble elements were often characterized by eddies with upstream flows up to $-0.11 \mathrm{~m} \cdot \mathrm{s}^{-1}$. Fish may be able to avoid downstream displacement in a river pulsed flow if there is adequate substrate to provide flow refugia, whereas in a river with little habitat complexity (similar to our Brett-type swim-tunnel trials) fish may have to swim faster against the pulse and eventually become fatigued and displaced. Several suckers were observed in the flume maintaining position by oral suction, suggesting that this species may not need to seek the slower velocities downstream of rocky substrate due to their unique cranial morphology and behavior (Myrick and Cech 2000). While fish may be able to avoid longitudinal displacement by taking refuge behind substrate or by oral suction, they would not be able to forage during this time, so repeated pulsed flows may result in lower food consumption and growth rates, and ultimately decreased survival rates.

Acknowledgements We thank D. Kratville, M. Fish, A. Kawabata, and M. Karagosian of Wildlife, Fish and Conservation Biology for technical and laboratory assistance; M.L. Kavvas, Z.Q. Chen, and H.A. Bandeh of UC Davis' J. Amorocho Hydraulics Laboratory for the use of the flume; the Center for Aquatic Biology and Aquaculture (CABA) at UC Davis for fish-holding facilities; Dennis Redfern, Frank Harris, and staff from the American River Trout Hatchery for the rainbow trout; Tim Salamunovich of Thomas Payne and Associates for technical methods assistance and constructive critiques; Mitchell Watnik for statistical analysis assistance; Douglas Conklin and Cincin Young of the Pulsed Flow Program Management Team; the Public Interest Energy Research Program (PIER) of the California Energy Commission; the Division of Water Rights of the State Water Resources Control Board, and the United States Bureau of Land Management for research support and encouragement. 
Open Access This article is distributed under the terms of the Creative Commons Attribution Noncommercial License which permits any noncommercial use, distribution, and reproduction in any medium, provided the original author(s) and source are credited.

\section{References}

Beamish FWH (1978) Swimming capacity. In: Hoar WS, Randall DJ (eds) Fish physiology, vol 7. Academic, New York, pp 161-187

Bell E, Duffy WG, Roelofs TD (2001) Fidelity and survival of juvenile coho salmon in response to a flood. Trans Am Fish Soc 130:450-458

Brett JR (1964) The respiratory metabolism and swimming performance of young sockeye salmon. J Fish Res Board Can 21:1183-226

Crisp DT (1991) Stream channel experiments on downstream movement of recently emerged trout, Salmo trutta L. and salmon, S. salar L.-III. Effects of developmental stage and day and night on dispersal. J Fish Biol 39:371-381

Crisp DT, Hurley MA (1991a) Stream channel experiments on downstream movement of recently emerged trout, Salmo trutta L. and salmon, Salmo salar L.-I. Effect of four different water velocity treatments upon dispersal rate. $\mathrm{J}$ Fish Biol 39:347-361

Crisp DT, Hurley MA (1991b) Stream channel experiments on downstream movement of recently emerged trout, Salmo trutta L. and salmon, Salmo salar L.-II. Effects of constant and changing velocities and of day and night upon dispersal rate. J Fish Biol 39:363-370

Danley ML, Mayr SD, Young PS, Cech JJ Jr (2002) Swimming performance and physiological stress responses of splittail exposed to a fish screen. North Am J Fish Manage 22:1241-1249

Giannico G, Healey M (1998) Effects of flow and food on winter movements of juvenile coho salmon. Trans Am Fish Soc 127:645-651

Goolish EM (1989) The scaling of aerobic and anaerobic muscle power in rainbow trout (Salmo gairdneri). J Exp Biol 147:493-505

Hammer C (1995) Fatigue and exercise tests with fish. Comp Biochem Physiol 112A:1-20

Harrelson CC, Rawlins CL, Potyondy, JP (1994) Stream channel reference sites: an illustrated guide to field technique. Gen Tech Rep RM-245 Fort Collins, CO. 61 p

Harvey BC (1987) Susceptibility of young-of-the-year fishes to downstream displacement by flooding. Trans Am Fish Soc 116:851-855
Heggenes J (1988) Effects of Short-term flow fluctuations on displacement of, and habitat use by, Brown trout in a small stream. Trans Am Fish Soc 117:336-344

Heggenes J, Traaen T (1988) Downstream migration and critical water velocities in stream channels for fry of four salmonid species. J Fish Biol 32:717-727

Irvine JR (1986) Effects of varying discharge on the downstream movement of salmon fry, Oncorhynchus tshawytscha Walbaum. J Fish Biol 28:17-28

Jeffres CA, Klimley AP, Merz JE, Cech JJ Jr (2006) Movement of Sacramento sucker, Catostomus occidentalis and hitch, Lavinia exilicauda, during a spring release of water from Camanche Dam in the Mokelumne River, California. Environ Biol Fish 75:365-373

Klimley AP, Cech, Jr JJ, Thompson LC, Hamilton S, Chun SN (2005) Experimental and field studies to assess pulsed, water-flow impacts on the behavior and distribution of fishes in California rivers, annual report, 2004-05. Prepared for the PIER Program Area, California Energy Commission. 107 p. http://www.energy.ca.gov/publica tions/displayOneReport.php?pubNum=CEC-500-2005172

McLaughin RL, Kramer DL (1991) The association between amount of red muscle and mobility in fishes: a statistical evaluation. Environ Biol Fish 30:369-378

Moyle PB (2002) Inland fishes of California. University of California Press, Berkeley

Myrick CA, Cech JJ Jr (2000) Swimming performances of four California stream fishes: temperature effects. Environ Biol Fish 58:289-295

Ottaway EM, Clarke A (1981) A preliminary investigation into the vulnerability of young trout (Salmo trutta L. and Atlantic salmon. S. salar L.) to downstream displacement by high water velocities. J Fish Biol 19:135-145

Ottaway EM, Forrest DR (1983) The influence of water velocity on the downstream movements of alevins and fry of brown trout, Salmo trutta L. J Fish Biol 23:221436

Shirvell CS (1994) Effects of changes in stream flow on the microhabitat use and movement of sympatric juvenile coho salmon (Oncorhynchus kisutch) and Chinook salmon (O. tshawytscha) in a natural stream. Can J Fish Aquat Sci 51:1644-1652

Young PS, Conklin DE, O'Hagan J, Canaday J, Cox C, Cech JJ Jr, Sih A, LC Thompson (2007) Hydropower-related pulsed flow impacts on stream fishes, amphibians, and macroinvertebrates. Prepared for California Energy Commission-Public Interest Energy Research Program, Sacramento, California, $38 \mathrm{p}$ 